\title{
Extrachromosomal DNA in Genome (in)Stability - Role of Telomeres
}

\author{
Lucia Nanić, Sanda Ravlić, Ivica Rubelj*
}

\author{
Department of Molecular Biology, Ruđer Bošković Institute, Bijenička c. 54, 10000 Zagreb, Croatia \\ * Corresponding author's e-mail address: rubelj@irb.hr
}

RECEIVED: February 22, 2016 * REVISED: May 5, 2016 * ACCEPTED: May 9, 2016

\section{EUKARYOTIC GENOME}

S IZE of eukaryotic genomes often are not correlated with their genetic complexity. These differences do not come from significant variation in the number of genes but rather from content of several types of non-coding sequences that make large part of the genome. Although the number and the size of chromosomes differ between eukaryotic species, their basic structure is identical for all eukaryotes. The DNA and corresponding proteins in the interphase nucleus is called chromatin. The degree of chromatin condensation changes throughout the cell cycle. Part of the chromatin that is relaxed in the interphase is called euchromatin and mostly contains active genes. The remaining $\sim 10 \%$ of the interphase chromatin represents heterochromatin which is condensed and transcriptionally suppressed because it mostly consists of highly repetitive DNA sequences. Thus, the structure of chromatin in eukaryotes is closely correlated with the control of gene expression.

During the cell division the chromatin progressively condenses forming metaphase chromosomes, in which the DNA density increases up to 10000 times. [1]

\section{THE REPETITIVE DNA CONTENT OF THE GENOME}

Repetitive sequences represent the most variable component which plays significant role in the complexity and dynamic of eukaryotic genomes. Approximately $50 \%$ of the human genome is comprised of repetitive DNA. Types of repetitive sequences can be determined based on the kinetics of their reassociation upon denaturation. ${ }^{[2-5]}$

Highly repetitive DNA represents $\sim 30-45 \%$ of mammalian DNA and reassociates quickly after denaturation. It consists of three subgroups of repetitive DNA. i) Satellite DNA is usually 100 kilo base (kb) to 1 mega base $(\mathrm{mb})$ long and spans centromeric areas. In human genome, alphoid satellite DNA with 171 base pairs (bp) long repeats occupies $3-5 \%$ of the genome and represents functional centromeric sequence. ii) Minisatellite DNA contains tandem repeats ranging in length from $10-60$ base pairs (bp) spanning 0.5 to several kb across the chromosome but more densely in centromeric and subtelomeric regions. iii) Microsatellites consist of short tandem repetitive units 1 to $6 \mathrm{bp}$ long and they usually do not exceed more than $150 \mathrm{bp}$ 
in length. When located in the vicinity of genes they may modulate their activity.

Sequences at the very ends of chromosomes are called telomeres. They represent the subgroup of short repeats specialized in its function to seal chromosome ends.

Interspersed repetitive DNA makes roughly $25-40 \%$ of mammalian DNA and reassociates slower than highly repetitive DNA. It includes repeats that are scattered throughout the genome. Often, they have the ability to change places and they belong to the group of mobile genetic elements. Two major types of mobile genetic elements in mammalian genomes are transposons and retrotransposons. Most common retrotransposable mobile elements in human genomes are long interspersed nuclear elements (LINEs) and short interspersed nuclear elements (SINEs) which are translocated by intermediateRNA. LINEs are $6-7 \mathrm{~kb}$ long, and SINEs are around $300 \mathrm{bp}$ in length. While LINEs encode a functional reverse transcriptase, SINEs depend on reverse transcriptase encoded by other mobile elements. The most common representatives of LINEs and SINEs repeats in human genome are L1 and Alu family, respectively. Although LINEs and SINEs are usually located in the regions without genes, some of them can also be found within introns. ${ }^{[6-8]}$ Some specialized retrotransposons serve as telomeres, mostly in insects, like non-LTR retrotransposons, HeT-A, TART and Tahre in Drosophila melanogaster. ${ }^{[9]}$

The unique (non-repetitive) sequences or sequences with very little repeats occupy $\sim 50-60 \%$ of mammalian DNA. Their reassociation after denaturation is the slowest. Part of the unique sequences are also most genes and various regulatory elements which actually build only $1-2$ $\%$ of entire genome. Most genes with specific function required in differentiated cells are present in two allelic copies while housekeeping genes important for basic metabolism and maintenance are often present in many copies, like clustered ribosomal genes.[10,11]

\section{EXTRACHROMOSOMAL DNA}

For a long time scientific community assumed that eukaryotic genome is very stable and defined regarding its sequence. According to this dogma, the genome was considered to be static and unable to immediately respond to environmental influences. The changes in the genome were considered to happen slowly over long period of time through evolutionary processes. As knowledge about the presence of various genomic sequences involved in amplification, repair, recombination or translocation processes increased, it became clear that the genome is much more unstable and more plastic than was previously thought. Often, changes in the genome structure include formation of extrachromosomal DNA. Indeed, in addition to organelle DNAs, a new population of DNA molecules, small in size and both linear and circular in shape has been identified and called extrachromosomal genomic DNA.[12-16]

All cells of multicellular organisms, tested so far, contained heterogeneous population of extrachromosomal circular DNA (eccDNA). Small circular DNA molecules have been described in various eukaryotes: Euglena, ${ }^{[17]}$ Trypanosoma, ${ }^{[18]}$ yeast, ${ }^{[19]}$ fungi, ${ }^{[20]}$ tobacco, ${ }^{[21]}$ Drosophila, [22] Xenopus, [23] chicken,,[23] mouse,[24] wild boar,, ${ }^{[12]}$ human tissue ${ }^{[13,25]}$ and human fibroblasts in culture. ${ }^{[26,15]}$ These molecules are also found in many other mammalian cell lines: mouse, ${ }^{[27]}$ rat, ${ }^{[28]}$ hamster ${ }^{[29]}$ or monkey. ${ }^{[14]}$ It appears, therefore, that the eccDNA is a general phenomenon in eukaryotic cells, in a similar way as the plasmids in prokaryotes (Table 1).

Usually, the total eccDNA comprises molecules of various sizes. Within the single cell type, circular DNA may vary from $500 \mathrm{bp}$ to more than 85000 bp. ${ }^{[30]}$ The number of eccDNA molecules per cell also varies widely, from 100 copies in human fibroblasts ${ }^{[31]}$ to several thousand copies in monkey kidney cell line. ${ }^{[32]}$

\section{ORGANIZATION OF EXTRACHROMOSOMAL CIRCULAR DNA}

Analysis of mammalian eccDNA using hybridization and sequencing techniques showed that all sequences have homology with the chromosomal DNA, but not with the mitochondrial DNA. eccDNA mostly contains repetitive sequences such as tandem repeat DNA, like satellite DNA, but also mobile genetic elements (LTR retrotransposons, non-LTR retrotransposons) and sequences with a small number of copies or unique DNA (see Table 1). Most abundant is middle repetitive DNA fraction. ${ }^{[33,27]}$ eccDNA derived from the alphoid satellite DNA is found in some unstable tumor cells like HeLa cell line but also in normal human diploid fibroblasts or green monkey BSC1 cells. ${ }^{[3,35,26]}$ In addition, HeLa and human cells contained separate groups of satellite sequences similar to alphoid family Sau3A. ${ }^{[36]}$ Centromeric satellite sequences are frequently present in eccDNA population in mouse cells in vivo and in vitro. ${ }^{[37,27]}$

\section{MECHANISMS OF ECCDNA FORMATION}

Repetitive sequences are probably involved in the formation of eccDNA for several reasons; some repetitive sequences are mobile genetic elements, others can participate in unequal crossing-over or intramolecular recombination through which they participate in chromosome/genome rearrangements. Since the sequences 
Table 1. Extrachromosomal circular DNA in mammalian cells ${ }^{[16]}$

\begin{tabular}{|c|c|c|c|c|}
\hline Organism & Cell type or tissue & $\begin{array}{l}\text { Number of eccDNA } \\
\text { per cell }\end{array}$ & Average lengths $(\mu \mathrm{m})$ & Types of DNA \\
\hline human & HeLa & $50-200$ & $0.8(0.2-2.5)$ & $\begin{array}{c}\text { alphoids, Sau3A, L1,THE-1, Alu and } \\
\text { unique DNA }\end{array}$ \\
\hline human & fibroblasts & $10-60$ & $1.5(0.1-7.6)$ & alphoids, Alu, L1 \\
\hline monkey & kidney, cell line BSC-1 & $1000-20000$ & $0.24(0.05-1.7)$ & alphoids, L1, Alu, and unique DNA \\
\hline hamster & $\mathrm{CHO}$ & ND & $1.5(0.09-7.0)$ & $\begin{array}{l}\text { tandem and intersperse repetitive DNA, } \\
\text { unique DNA }\end{array}$ \\
\hline rat & mioblasts L6 & 400 & $0.6(0.1-2.5)$ & ND \\
\hline mouse & L & 1200 & $0.6(0.2-2.4)$ & ND \\
\hline mouse & $3 T 6$ & ND & $0.7(0.1-3.8)$ & satellites, L1, B1 and B2 \\
\hline mouse & tymocites & ND & $5.4(0.2-2.4)$ & $\begin{array}{l}L 1, B 1 \text {, sequences with very little } \\
\text { repeats, gen } \beta \text { for } T \text {-st receptor }\end{array}$ \\
\hline mouse & heart & ND & $0.8(0.2-2.4)$ & satellites, L1, IAP, B1 and B2 \\
\hline mouse & liver & ND & ND & satellites, IAP, B1 and B2 \\
\hline mouse & brain & ND & ND & $\begin{array}{c}\text { satellites, } L 1, I A P, \\
B 1 \text { and } B 2\end{array}$ \\
\hline
\end{tabular}

within eccDNA population are very diverse, it is reasonable to expect that there is more than one mechanism of their formation and that they can be created from a variety of genomic sequences.

Part of the DNA can be cut out of the genome and rounded in intrachromosomal recombination between repetitive sequences. First proposed mechanism for this event was homologous recombination between direct repeats. ${ }^{[15]}$ Circular loop occurs when two direct repeats align in the orientation appropriate for homologous recombination. If there are more successive repeats, eccDNA with multiple repetitive sequences will form. Organization of repeats of Sau3A family and alphoid satellite DNA within extrachromosomal circles in human cells indicates such mechanism of eccDNA creation. ${ }^{[38,39]}$ Investigation of cellfree system of Xenopus laevis oocytes has shown that eccDNA occurs de novo, independently from replication of chromosomal DNA. This eccDNA is formed from sequences containing direct tandem repeats. ${ }^{[40]}$

eccDNA containing unique sequence can be created if homologous recombination occurs between repetitive sequences flanking unique one. Several eccDNA from mammalian cells support this model of recombination. ${ }^{[41]}$ Circular DNA containing sequences with a small number of repetitions or unique sequences can occur by recombination of consecutive repeats without complete homology as well. ${ }^{[42]}$

Repeats oriented in opposite directions also contribute to recombination events and creation of eccDNA, and it is believed that they play an important role in gene amplification. ${ }^{[43]}$
Since some of the eccDNA from HeLa cells that contains unique sequences has no direct nor inverted repeats at the site of recombination, it points to non-homologous recombination as another possible mechanism of eccDNA creation. ${ }^{[44]}$ Some agents like cycloheximid and puromycin cause increase of eccDNA in cultured cells, and same effect was observed when the culture was kept in stationary phase of growth for longer period of time. ${ }^{[34]}$ Agents that cause DNA damage have similar effects. ${ }^{[45]}$

\section{ROLE OF ECCDNA IN GENOME INSTABILITY}

The genome is under constant influence of destabilizing factors, including normal mechanisms of DNA replication and cell division, as well as numerous intracellular and extracellular stressors like oxidative metabolism or genotoxic agents and environmental radiation. Therefore, cells have developed various mechanisms in order to preserve integrity of the genome; especially important are high fidelity DNA replication, DNA damage repair and cell cycle control mechanisms. Any error in these processes can lead to destabilization of the genome, increased rate of mutations or can lead to aberrant cellular functions, which ultimately may cause cell death. Genomic instability represents continuous changes in the genome, which include various structural changes such as translocation, aneuploidy, recombination, deletions, gene amplification and, as mentioned above, generation of eccDNA. The later one may not necessarily represent abnormalities. Large chro- 


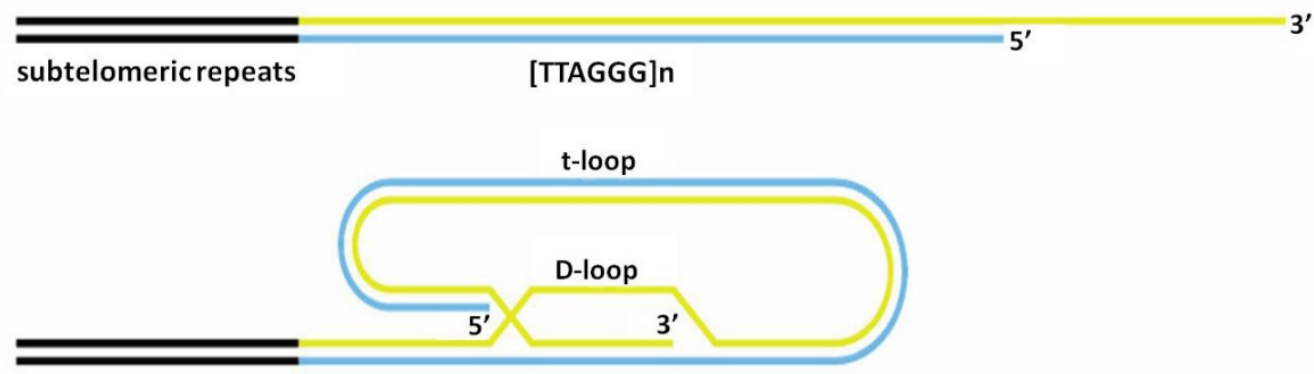

Figure 1. Telomere loop structure (see text for details).

mosomal aberrations, such as circular and dicentric chromosomes or large chromosomal deletions are usually lethal for dividing cell. In contrast, smaller aberrations that do not jeopardize cell viability are transmitted through cell generations.

Genome instability is typical for carcinogenesis and is often characteristic of tumor cells, while is rarely observed in normal cells. It is perceived as necessary event that occurs early in the development of the tumor, leading to neoplastic transformation. Rare genetic diseases with a high predisposition for tumor development, such as Fanconi anemia, xeroderma pigmentosum and ataxia telangiectasia, are characterized with defective DNA repair which causes genome instability accompanied with accumulation of eccDNA. ${ }^{[46,47]}$ Also, carcinogens and substances which interfere with DNA synthesis increase the amount of eccDNA in normal human fibroblasts. ${ }^{[48]}$ Thus, eccDNA is a good indicator of genome instability, caused either by endogenous mutations or harmful environmental agents.

\section{ROLE OF TELOMERES IN GENOME (IN)STABILITY}

Telomeres are physical ends of linear chromosomes. They are nucleoprotein complexes important for protection, replication and stabilization of chromosomes. Specific lariat structure of telomeres prevents chromosomal aberrations (translocations, deletions, chromosome fusions etc.) and protects the chromosome ends from DNA damage repair enzymes, which makes telomeres directly responsible for the stability of the eukaryotic genome. ${ }^{[49,50]}$ Telomere sequence consists of repetitive TTAGGG motifs present in all vertebrates. They vary in size from species to species and in humans are on average $15 \mathrm{~kb}$ long. ${ }^{[51]}$ Telomeres end with single stranded 3 '-protruding end, rich in guanines, which is important for the formation of telomere loop (tloop) ${ }^{[52,53]}$ (Figure 1).

Telomeres are dynamic structures. At each cell division they shorten due to the nature of DNA replication process at which DNA polymerase holoenzyme cannot synthesize the very end of linear chromosomes. ${ }^{[54]}$ Thus, with the accumulation of cell divisions, telomeres are progressively shortened. Telomere shortening has been demonstrated both in vitro and in vivo. ${ }^{[49,55,56]}$ When telomeres shorten to their critical length, they can no longer protect the ends of chromosomes. This process is of particular importance because such telomere is recognized by DNA damage response mechanisms which permanently stop cell division in the $\mathrm{G} 1$ phase of the cell cycle, causing cellular aging. ${ }^{[57,58]}$ Most often, immortal cells avoid this scenario by expression of enzyme telomerase, specialized for telomere elongation. ${ }^{[59]}$

\section{EXTRACHROMOSOMAL CIRCULAR TELOMERE DNA}

Extrachromosomal, often circular, copies of telomere sequences were found in many organisms, including yeasts, plants, amphibians and some mammalian cell lines. ${ }^{[60]}$ The amount of telomeric eccDNA is higher in transformed cells than in normal cells of rodents, and it is greatly increased after treatment with carcinogens. Telomeric eccDNA is detected in some human tumors and cell lines, which suggests that it is not common phenomenon in transformed human cells. Research on human immortal cell lines without active telomerase, which use alternative mechanism based on recombination to extend their telomeres $(A L T)^{[61]}$ showed the presence of small linear ${ }^{[62,63]}$ and circular double strand eccDNA with telomeric sequences in both the cytoplasm and nucleus, while these were not observed in normal fibroblasts. ${ }^{[64]}$ Telomere eccDNA found in the nucleus is in complex with telomere binding proteins like telomere repeat factor 1 (TRF1), telomere repeat factor 2 (TRF2) but also with recombination Mre11-Rad50-Nbs1 (MRN) complex. ${ }^{[63]}$ It was found in cells from patients with ataxia telangiectasia disease, defective in DNA repair. ${ }^{[65]}$

Telomere sequences present as eccDNA are considered to be indicator of genomic instability, ${ }^{[66]}$ but they also may have an important role in maintaining telomere 


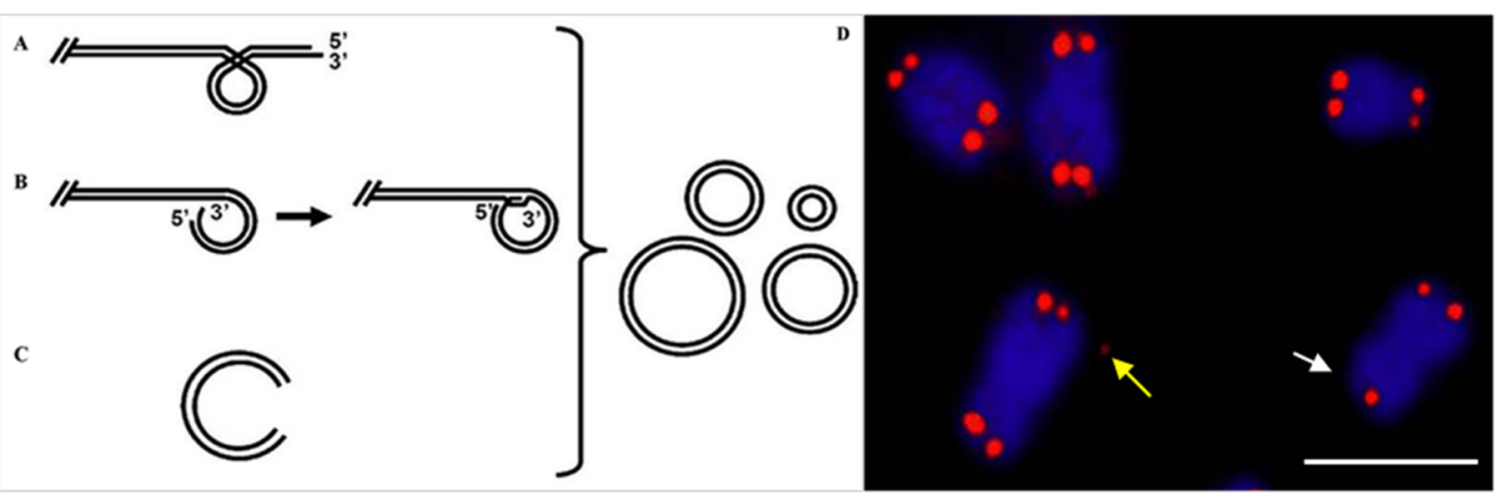

Figure 2. Possible mechanisms of creation of extrachromosomal telomeric circular DNA; A) intra-homologous recombination between telomere repeats, B) an intra-homologous recombination within telomere loop (t-loop), C) circularization of extrachromosomal linear telomeric DNA. ${ }^{[60]}$ D) Recombinational event in the cell resulting in formation of extrachromosomal telomeric circular DNA (PNA-FISH). White arrow points to the chromosome that lacks one telomere signal. Yellow arrow points to free telomere signal. Bar $10 \mu \mathrm{m}$.

length in some cells. ${ }^{[67]}$ The existence of eccDNA with telomeric sequences is explained with intra-homologous recombination between telomere repeats, an intra-homologous recombination within telomere loop (t-loop) or circularization of extrachromosomal linear telomeric DNA ${ }^{[60]}$ (Figure $2 \mathrm{~A}, \mathrm{~B}, \mathrm{C}$, respectively). An example of such recombination event in the cell is shown in Figure $2 \mathrm{D}$.

\section{ROLE OF EXTRACHROMOSOMAL CIRCULAR TELOMERE DNA IN CELL SENESCENCE}

Early experiments have shown that the populations of normal human fibroblasts in culture are very heterogeneous regarding their cell growth potential. ${ }^{[68]}$ On individual cell level, even two daughter cells arising from the same mitosis show great variation in population doublins (PDs). ${ }^{[69]}$ These results could not be explained by the gradual shortening of telomeres due to incomplete replication of chromosome ends. A theoretical model of abrupt telomere shortening (ATS), has been proposed which predicts recombination event on telomeres in normal human cells. ${ }^{[70,71]}$ As a result, extrachromosomal circular telomere DNA or t-circles, are formed. Most common method for detection of $\mathrm{t}$-circles is two-dimensional (2D) gel electrophoresis. This method showed presence of t-circles in some tumor cell lines, human fibroblasts carrying mutations on certain genes associated with telomeres and hTERT immortalized cells, ${ }^{[48,64,72-76]}$ but still it never showed their presence in normal human cells. ${ }^{\text {[72] }}$

Using reaction for amplification of telomeric circular DNA, which is ten times more sensitive than 2D gel electrophoresis, we were able to detect t-circles in normal human skin fibroblasts MJ90 and normal human lung fibroblasts IMR90. ${ }^{[77]}$ Unlike in ALT U2OS cells where $\mathrm{t}$-circles can easily be detected by $2 \mathrm{D}$ gel electrophoresis, ${ }^{[73,72]}$ their low presence in human fibroblasts MJ90 showed that rapid telomere deletion is a rare event in normal cells. A rough estimate shows that only less than $0,005 \%$ of telomeres can undergo abrupt shortening per one cell division in these cells which is below the level of detection of 2D gel electrophoresis. Nevertheless, simulation of abrupt telomere shortening showed that these rare events have a major impact on the growth dynamics of normal cell cultures. ${ }^{[78,71]}$ Analysis of total telomere length in fractions of young and old cells isolated from the same culture showed that the average telomere length in these two fractions is the same. This supports the idea that stochastic appearance of senescent cells in normal cell culture is a consequence of abrupt telomere shortening rather than gradual loss of telomere repeats. [66]

Acknowledgment. We thank to Nevenka Meštrović for critically reading the manuscript and valuable suggestions.

\section{REFERENCES}

[1] S. Bruno, H. A. Crissman, K. D. Bauer, Z. Darzynkiewicz, Exp. Cell Res. 1991, 196, 99.

[2] C. Ramel, Environ. Health Perspect. 1997, 105 Suppl, 781.

[3] H. Fulka, A. Langerova, Development 2014, 141, 1694.

[4] A. Jansen, R. Gemayel, K. J. Verstrepen, Genome Dyn. 2012, 7, 108.

[5] F. Giraudeau, F. Apiou, V. Amarger, P. J. Kaisaki, M. T. Bihoreau, M. Lathrop, G. Vergnaud, D. Gauguier, Mamm. Genome 1999, 10, 405.

[6] D. Chalopin, M. Naville, F. Plard, D. Galiana, J.-N. Volff, Genome Biol. Evol. 2015, 7, 567. 
[7] S. Gallus, B. M. Hallstrom, V. Kumar, W. G. Dodt, A. Janke, G. G. Schumann, M. A. Nilsson, Mol. Biol. Evol. 2015, 32, 1268.

[8] Y. Li, S. Liang, H. Liu, Y. Sun, L. Kang, Y. Jiang, Anim. Genet. 2015, 46, 437.

[9] M.-L. Pardue, S. Rashkova, E. Casacuberta, P. G. DeBaryshe, J. A. George, K. L. Traverse, Chromosome Res. 2005, 13, 443.

[10] S. Ide, T. Miyazaki, H. Maki, T. Kobayashi, Science 2010, 327, 693.

[11] D. M. Stults, M. W. Killen, H. H. Pierce, A. J. Pierce, Genome Res. 2008, 18, 13.

[12] Y. Hotta, A. Bassel, Proc. Natl. Acad. Sci. U. S. A. 1965, 53, 356.

[13] R. Radloff, W. Bauer, J. Vinograd, Proc. Natl. Acad. Sci. U. S. A. 1967, 57, 1514.

[14] M. G. Rush, R. Eason, J. Vinograd, Biochim. Biophys. Acta 1971, 228, 585.

[15] C. A. Smith, J. Vinograd, J. Mol. Biol. 1972, 69, 163.

[16] J. W. Gaubatz, Mutat. Res. 1990, 237, 271.

[17] M. M. Nass, Y. Ben-Shaul, Biochim. Biophys. Acta 1972, 272, 130.

[18] T. Ono, Y. Ozeki, S. Okubo, S. Inoki, Biken J. 1971, 14, 203.

[19] F. E. Billheimer, C. J. Avers, Proc. Natl. Acad. Sci. U. S. A. 1969, 64, 739.

[20] E. Agsteribbe, A. M. Kroon, E. F. J. Van Bruggen, Biochim Biophys Acta 1972, 269, 299.

[21] F. Y. Wong, S. G. Wildman, Biochim. Biophys. Acta 1972, 259, 5.

[22] S. Stanfield, D. R. Helinski, Cell 1976, 9, 333.

[23] M. Buongiorno-Nardelli, F. Amaldi, P. A. LavaSanchez, Exp. Cell Res. 1976, 98, 95.

[24] H. Yamagishi, T. Kunisada, Y. Iwakura, Y. Nishimune, Y. Ogiso, A. Matsushiro, Dev. Growth Differ. 1983, 25, 563.

[25] B. Calabretta, D. L. Robberson, H. A. BarreraSaldana, T. P. Lambrou, G. F. Saunders, Nature 1982, 296, 219.

[26] K. Riabowol, R. J. Shmookler Reis, S. Goldstein, Nucleic Acids Res. 1985, 13, 5563.

[27] P. Sunnerhagen, R. M. Sjöberg, A. L. Karlsson, L. Lundh, G. Bjursell, Nucleic Acids Res. 1986, 14, 7823.

[28] T. Kunisada, H. Yamagishi, T. Sekiguchi, Plasmid 1983, 10, 242.

[29] S. W. Stanfield, D. R. Helinski, Mol. Cell. Biol. 1984, 4, 173.

[30] H. Yamagishi, T. Tsuda, S. Fujimoto, M. Toda, K. Kato, Y. Maekawa, M. Umeno, M. Anai, Gene 1983, 26, 317.

[31] T. Kunisada, H. Yamagishi, Z. Ogita, T. Kirakawa, Y. Mitsui, Mech. Ageing Dev. 1985, 29, 89.

[32] R. J. DeLap, M. G. Rush, D. Zouzias, S. Khan, Plasmid 1978, 1, 508.
[33] S. W. Stanfield, J. A. Lengyel, Proc. Natl. Acad. Sci. U. S. A. 1979, 76, 6142.

[34] A. H. Bertelsen, M. Z. Humayun, S. G. Karfopoulos, M. G. Rush, Biochemistry 1982, 21, 2076.

[35] T. Kunisada, H. Yamagishi, J. Mol. Biol. 1987, 198, 557.

[36] R. Kiyama, H. Matsui, M. Oishi, Proc. Natl. Acad. Sci. U. S. A. 1986, 83, 4665.

[37] S. C. Flores, P. Sunnerhagen, T. K. Moore, J. W. Gaubatz, Nucleic Acids Res. 1988, 16, 3889.

[38] R. S. Jones, S. S. Potter, Nucleic Acids Res. 1985, 13, 1027.

[39] R. Kiyama, H. Matsui, K. Okumura, M. Oishi, J. Mol. Biol. 1987, 193, 591.

[40] S. Cohen, M. Mechali, Nucleic Acids Res. 2001, 29, 2542.

[41] R. S. Jones, S. S. Potter, Proc. Natl. Acad. Sci. U. S. A. 1985, 82, 1989.

[42] S. W. Stanfield, D. R. Helinski, Nucleic Acids Res. 1986, 14, 3527.

[43] S. Cohen, D. Hassin, S. Karby, S. Lavi, Mol. Cell. Biol. 1994, 14, 7782.

[44] N. van Loon, D. Miller, J. P. Murnane, Nucleic Acids Res. 1994, 22, 2447.

[45] P. Sunnerhagen, R. M. Sjoberg, G. Bjursell, Somat. Cell Mol. Genet. 1989, 15, 61.

[46] E. R. Fearon, Science 1997, 278, 1043.

[47] L. Hartwell, Cell 1992, 71, 543.

[48] S. Cohen, A. Regev, S. Lavi, Oncogene 1997, 14, 977.

[49] E. H. Blackburn, Nature 1991, 350, 569.

[50] A. Cukusic Kalajzic, N. S. Vidacek, M. Huzak, M. Ivankovic, I. Rubelj, PLoS One 2014, 9, e92559.

[51] M. Laganovic, L. Bendix, I. Rubelj, M. V. Kirhmajer, N. Slade, I. V. Lela, V. Premuzic, P. M. Nilsson, B. Jelakovic, J. Hypertens. 2014, 32, 1613.

[52] J. D. Griffith, L. Comeau, S. Rosenfield, R. M. Stansel, A. Bianchi, H. Moss, T. de Lange, Cell 1999, 97, 503.

[53] C. W. Greider, Cell 1999, 97, 419.

[54] A. M. Olovnikov, Dokl. Akad. Nauk SSSR 1971, 201, 1496.

[55] C. B. Harley, A. B. Futcher, C. W. Greider, Nature 1990, 345, 458.

[56] M. Ivankovic, A. Cukusic Kalajzic, N. Skrobot Vidacek, I. Franic Simic, S. Davidovic Mrsic, I. Rubelj, Biogerontology 2012, 13, 203.

[57] L. Bendix, P. B. Horn, U. B. Jensen, I. Rubelj, S. Kolvraa, Aging Cell 2010, 9, 383.

[58] M. Matulić, M. Sopta, I. Rubelj, Cell Prolif. 2007, 40, 462.

[59] M. Ivankovic, A. Cukusic, I. Gotic, N. Skrobot, M. Matijasic, D. Polancec, I. Rubelj, Biogerontology 2007, 8, 163.

[60] L. Tomaska, M. J. McEachern, J. Nosek, FEBS Lett. 2004, 567, 142. 
[61] N. Skrobot Vidacek, A. Cukusic, M. Ferenac Kis, M. Ivankovic, I. Jevtov, S. Mrsic, I. Rubelj, Cytogenet. Genome Res. 2007, 119, 60.

[62] H. Ogino, K. Nakabayashi, M. Suzuki, E. Takahashi, M. Fujii, T. Suzuki, D. Ayusawa, Biochem. Biophys. Res. Commun. 1998, 248, 223.

[63] Y. Tokutake, T. Matsumoto, T. Watanabe, S. Maeda, H. Tahara, S. Sakamoto, H. Niida, M. Sugimoto, T. Ide, Y. Furuichi, Biochem. Biophys. Res. Commun. 1998, 247, 765.

[64] A. J. Cesare, J. D. Griffith, Mol. Cell. Biol. 2004, 24, 9948.

[65] M. P. Hande, A. S. Balajee, A. Tchirkov, A. WynshawBoris, P. M. Lansdorp, Hum. Mol. Genet. 2001, 10, 519.

[66] A. Regev, S. Cohen, E. Cohen, I. Bar-Am, S. Lavi, Oncogene 1998, 17, 3455.

[67] L. Tomaska, J. Nosek, A. M. Makhov, A. Pastorakova, J. D. Griffith, Nucleic Acids Res. 2000, 28, 4479.

[68] G. M. Martin, C. A. Sprague, T. H. Norwood, W. R. Pendergrass, Am. J. Pathol. 1974, 74, 137.

[69] J. R. Smith, R. G. Whitney, Science 1980, 207, 82.
[70] I. Rubelj, Z. Vondracek, J. Theor. Biol. 1999, 197, 425.

[71] I. Rubelj, M. Huzak, B. Brdar, O. M. Pereira-Smith, Biogerontology 2002, 3, 213.

[72] R. C. Wang, A. Smogorzewska, T. de Lange, Cell 2004, 119, 355.

[73] Z. Deng, J. Dheekollu, D. Broccoli, A. Dutta, P. M. Lieberman, Curr. Biol. 2007, 17, 1989.

[74] S. A. Compton, J.-H. Choi, A. J. Cesare, S. Ozgur, J. D. Griffith, Cancer Res. 2007, 67, 1513.

[75] B. Li, S. P. Jog, S. Reddy, L. Comai, Mol. Cell. Biol. 2008, 28, 1892.

[76] Y. Wang, G. Ghosh, E. A. Hendrickson, Proc. Natl. Acad. Sci. U. S. A. 2009, 106, 12430.

[77] N. S. Vidacek, A. Cukusic, M. Ivankovic, H. Fulgosi, M. Huzak, J. R. Smith, I. Rubelj, Exp. Gerontol. 2010, 45, 235.

[78] I. Rubelj, M. Huzak, B. Brdar, Mech. Ageing Dev. 2000, 112, 233.

[79] M. Ferenac, D. Polančec, M. Huzak, O. M. PereiraSmith, I. Rubelj, Journals Gerontol. Ser. A Biol. Sci. Med. Sci. 2005, 60, 820. 